\title{
Mobility and the role of the automobile as the central device in modern North American residential spatial planning
}

\author{
A. Furman \\ Faculty of Communication \& Design, Ryerson University, Canada
}

\begin{abstract}
The accumulation of space needed for our vehicles after a century of modern and postmodern planning and construction merit some review of our early fascination towards the place of the car in our homes and lifestyles. Beginning with the interior, the carport, the car, and the city itself, this paper will describe how the design of our North American dwellings focus on the automobile, and what this says about our present and future growth. Looking at some of the key voices of the early modern era, it will be demonstrated that the relationship of the automobile to domesticity was a close one, yet the larger role of the architect in the conversion of city space to facilitate flows and movement patterns that centred on the car was opportunistic and even naïve.

Was the idea of 'street' excised from space planning in modernism so that all troubles would be solved by unimpeded access for the car? How was the presence of the car styled to effectively disappear in order to amplify the experience architecturally? Looking at some of the work and ideas of Ludwig Mies van der Rohe, Le Corbusier, and Frank Lloyd Wright, a pattern will emerge in each architect's approach - to respond to planned urban form with one's own version that is publicly viewed or to keep to only a suggestion of where things might be headed, and illustrate this in your built architecture.

Keywords: modernism, automobile dependency, free plan, circulation, materiality, garage, mobility, sprawl, suburbs, urban lifestyle, utopia, active transportation, ideal plan, community, panorama, architectural promenade, Ludwig Mies van der Rohe, Le Corbusier, Frank Lloyd Wright.
\end{abstract}




\section{From the garage to the central business core}

It is neither in the house nor out of the house but of the house and somewhere in between, just as it sits between the house and the suburb. It is an open interior space, not exactly neutral, between inside and outside: the zone of transition, the transitional passage, the residence of transit, the exit and the entrance (double doors), the social airlock for car culture...

Snider, The Garage [1].

There was no need for a garage because she did not drive.

Schwartz, Vanna Venturi House [2].

The interior landscape of a car is a malleable thing. It is promoted as a mover of people and their cargo and yet it has become a place in-between - it is a temporary home for the life that makes up our daily rituals; it is an office, breakfast area, impromptu conversational seating, it is one's den, a makeshift make-up counter, entertainment zone, rehearsal space, a place for meetings and interviews, it is observation deck, and also a room of one's own.

The car promised only a quick transport from point a to b, the adaptations of use to it have come about through our compressed experience of time. The visions for a new modern world created a space of object buildings in a matrix of open spaces, gridded with high-speed roads - what would become of longestablished forms of community, conviviality, culture and a public realm within the context of the city schemes by the early modernists who promoted the erasure of the classic street, and by extension the relationship of distances between the centre and the edge (of a city)? It seems that the hand-drawn perspectives offered in the design of the new modern world were often taken overlooking private courtyards or high atop balconies; seldom was a view shown at the street level, where one would go to find a local convenience or enjoy the unfolding sequence of space that a vibrant (existing) street offered. And yet paradoxically these early modernist interiors are so replete with sensual affect in the use of various materials, colours, control of natural light and in the setting up of desirable prospects using large plate glass. The designers of these modern interiors still utilized traditional spatial strategies found in historic architectural schemes: pathways, variety, hierarchy, sequence of space, layering of foreground and background, manipulation of scale, focus, etc. It is as if they designed these early beautiful homes to be aquariums to contain the vanishing old-world public city street life - streets for short walks threatened by war, manifestos and future visions in Europe, realized in many North American cities through single-use zoned planning and in the demolition of the historic core.

Influential architects from the early modernist era did wield a great amount of influence not only in what they designed, but also in what they chose not to directly participate in or influence the policy of public spaces - street life and the connectivity of the public realm beyond the privately used lands. Modernity had a direct role to play by emphasizing the individual building and minimizing the 
connective spaces between individual buildings as a shared commons. The use of images and the forms of promotion of the modern in architecture was a wellcrafted enterprise, and it resulted in the public consumption of these images of private contemporary homes and buildings 'fit' for modern living [3]. The contemporary world (fig. 1) works quite differently - news, opinions and architectural manifestos tend to get lost in the crowd of online traffic. Since there are so many diverse voices, there isn't a cohesive style of architecture or planning, as there was in the first half of the twentieth century. And in that era there were arguably a few architects, who rose to public prominence spanning continents, indirectly influencing planning policies while their personal brand grew with each decade; they exhibited their influence in sometimes subtle and other times very public ways.

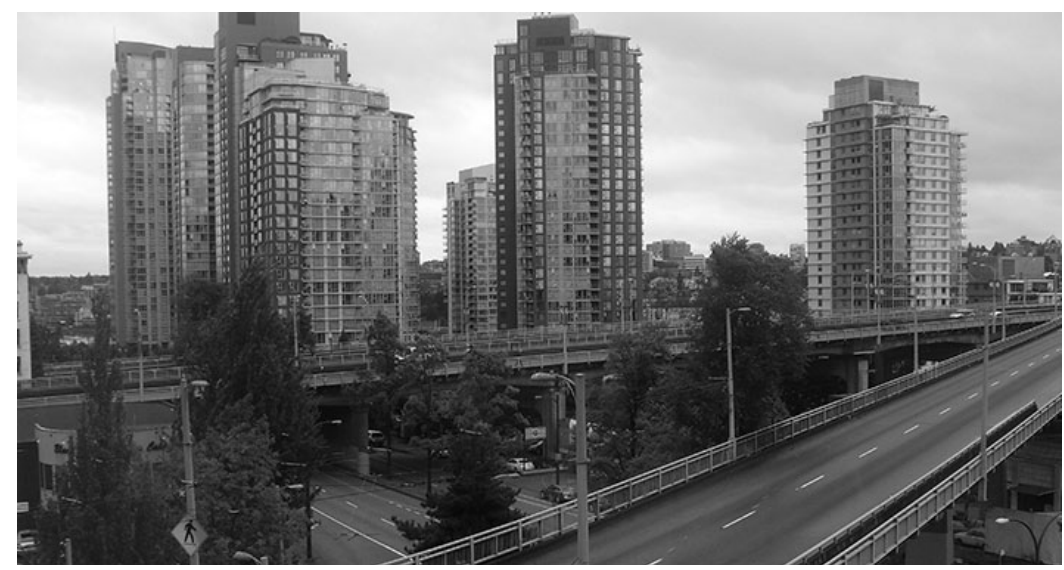

Figure 1: Image of the contemporary city.

1893 was a watershed moment in modernism - a young Frank Lloyd Wright caught moonlighting at his full-time job by Sullivan, his employer, is either fired or quits and decides to open up his own office that same year, Henry Ford completes his first gas motor in Detroit, the Duryea brothers become the first to drive a car in North America. Henry Ford is getting ready to go public with his ideas of a more affordable automobile that will transform the continent and how streets are perceived forever. Modernism and the car started on the same path and both have never looked back.

Mies van der Rohe, Le Corbusier, and Frank Lloyd Wright have had powerful undisputed influence in North America in the twentieth century. Their collective energy propelled modernism forward as an avant-garde approach to living in the present. It also had ripple effects; it became the de facto style-watered down (the international style) for less expensive projects across the land, as a style for all things contemporary for almost all structures except, to the frustration of designers everywhere- the single family home. Here modern style was almost completely rejected by the growing middle-class for something that didn't remind them of their recent place of work - the city; they wanted their home to 
look comforting, that is to say familiar, not mysterious and masked but textured, and it had to have a driveway and a garage in order to function.

\section{Urban space pared down to interiors}

Mies van der Rohe, Born in Aachen, Germany (1886-1969) was a GermanAmerican architect of classical sensibilities who desired above all else the types of commissions that were not a multi-purpose stew of programs and users and those who were considering incremental designs that might be added to the original structure. His preferred building type was the single-family house or art gallery. Later in his career he became a permanent resident of the United States, leaving the Germany of the 1930s to pursue his career where modernist ideals would find a welcome reception. He received institutional planning and corporate towers that were carefully articulated works of building art in glass and steel. Implicit in all of his work was an acceptance of the automobile and how it is transforming all modern space. He accepted this, as did most other modernists in the same way someone accepts an improvement to a toaster or television inevitable and as a sure sign of progress and freedom.

There is a tendency in his work, residential, commercial and other, to heighten the experience one has from a stationary place indoors yet imbue the spaces with specific experiences akin to being in an automobile - this can be seen in portions of the Farnsworth House (1945-51). This was a one room weekend and summerhouse not too far off from Chicago for Dr. Edith Farnsworth, in Plano, Illinois. It is one of his most refined homes in America or otherwise. He wanted all his work to be in the present and he said "I have tried to make an architecture for a technological society" [4]. This weekend house was built for 1 person to enjoy nature and it was an example of the total separation of the city and signs of roadways snaking into the key views. Mies set up the siting so one would need to park a good distance away and then proceed by foot to the house, surrounded by trees and a river. The expressed steel columns that float the home above the ground to (almost) evade the floodplain, as if the house is wrestling itself free from gravity so as to be entirely separate from nature yet paradoxically surrounded by it.

Modern planning virtues were kept pure in his designs; very little space is afforded for storage and the accumulation of clutter, reminiscent of a temple or timeless space, and an individual is imagined as anyone - generic, a non-specific personality. This might be compared to the anonymity that is desirable to someone when they are seen driving in an automobile - one's identity is cloaked behind the glass and steel, and the individual becomes a silhouette, a generic form; the car's ability to render anyone instantly into a universal-international type. One cannot 'pick out' a driver driving in the same way that you can spot someone familiar in a large crowd based on their form and the manner that they walk.

Mies' appropriation of the car into the modern home is seen most dramatically in the unrealized courtyard house design of 1934 (fig. 2). The diagram above shows that parking becomes the heart of the plan (rectangular 


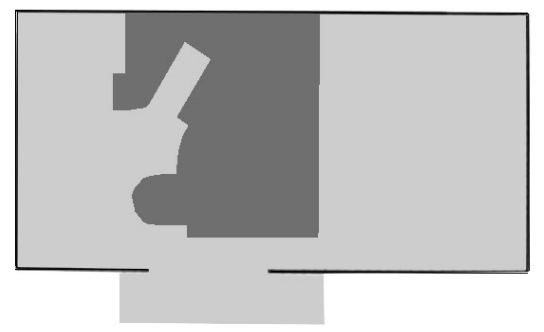

Figure 2: Diagram of Mies’ 1934 courtyard plan proposal, note garage location.

area removed from the darker mass), accepting the vehicle in a mechanical, and in so doing challenging the primacy of the traditional hearth and living area of the home. It is quite a departure for Mies. He seems to be grappling with the role of the car more so in this design. It isn't as resolved a sequence of spaces as is the Brno family home that layers carefully orchestrated paths for the family, maid, chauffeur and guests in the interior and exterior realms. It seems the enclosure denies being 'just a garage' and isn't quite sure how to deal with the car's bulk.

Villa Tugendhat in Brno, Czech Republic (1928-30) has been faithfully restored very recently (2012). This family home demonstrates how far Mies was capable of perfecting finishes and subtle technological effects that were hidden from view. From the street level on the north side, a sombre garage door welcomes the chauffeur zone adjacent to a central court and a hidden entryway covered by a roof that alludes to a carport. This setting, where a vehicle may temporarily park manages to eclipse even the most daring car commercial - here you have the approach, arrival of the car, the neutral architectural platonic shapes cradling the vehicle and all the while framing the distant view of nature.

Bold and uniquely designed cruciform columns that allowed for the free flow of space were clad in a warm bronze patina in the exterior, while the interior columns are treated differently- they borrow from the language of the car; the bronze is chrome plated and reflects all light and colour indoors. This design distinction between inside and outside seems to defer to the chrome of the car parked outside so as not to compete with it in spirit or finish. While inside, the chrome reifies the progress of the modern car by bringing this finish up close to the resident. One sits (also on metal that is chromed), has meals, and entertains beside the chrome columns and the carefully selected ebony wood, leather seats, smooth floor, milk glass and onyx wall. Mies adds two futuristic elements that anticipates comfort and climate-control in vehicles: the now ubiquitous automatic windows - in this remarkable building the entire southwest living room wall of glass can retract into the floor with the touch of a button, leaving the living area as an inside-outside experience. Another first is air-conditioning, utilizing a system of air that is blown over river stones and pine needles to create a fresh air scent. One may recall with irony the 'little tree' air freshener that adorned so many rear-view mirrors, offering a similar scent-experience but in a 
very different context. Planning and compartmentalization of mechanical areas are separated to maximize open areas for sociability are masterfully controlled and again speak about an approach to mechanical spaces where engines and boilers are sequestered away from sight so that the living can go on in a way that maximizes comfort.

Did Mies privately concern himself with the growing issues of planning problems related to 'donut cities' (a classic mid-century urban problem where commuters leave and few residents remain) and sprawl later in his career - did he envisage any role for himself to bring some solutions to the planning orthodoxy of the day? He chose to concentrate on the building of buildings, separating his practice- his theory from the messy and politicized discussions of how the entire system is tied together. This is also part of his legacy as a theoretical figure and influential maker of space, for the planning and building establishment saw hordes of copies of his formal language in office towers and residential high rises. All came with multi-level carports that were hidden from view and (also) from discussions about planning, and few schemes attempted to grapple with the issues of the public realm and interconnectedness of their work to the larger picture. It is a pity because he would have had much to offer if his public spaces could solve the modern issues of flow as well as his interior and homes managed to do (fig. 3). It would be novel to find a sketch by Mies that provides delight in moving through the city by foot along with mechanical systems for a solution to a modern city street from his residential design era.

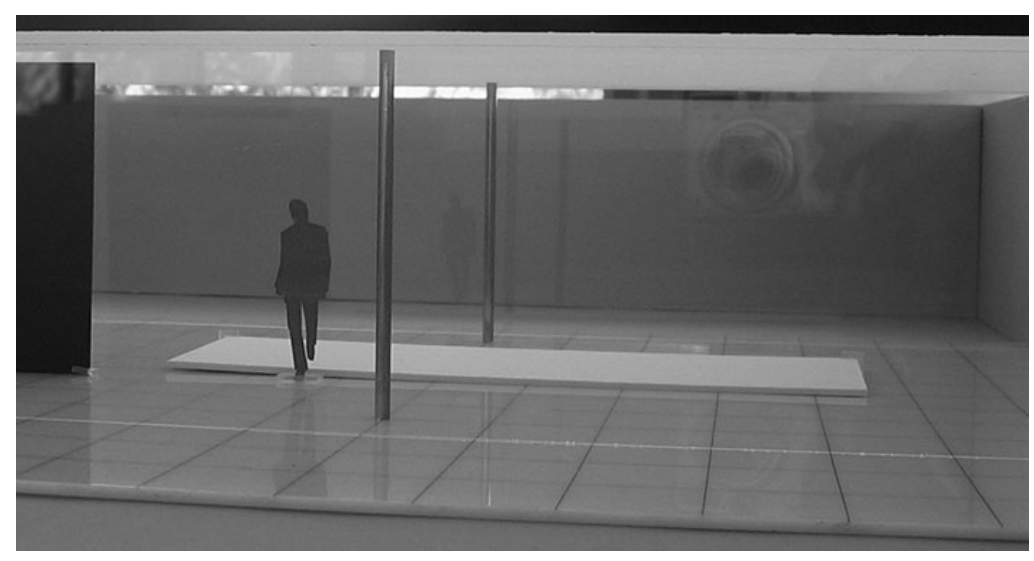

Figure 3: $\quad$ Scale model of a conceptual Mies courtyard residence.

\section{Floating the garden - promoting a new type of city life}

Le Corbusier (1887-1965) was born in La Chaux de-Fonds, Switzerland and like Mies and Frank Lloyd Wright he had cultivated a powerful public persona. Corbusier was interested in all forms of design, from painting, furniture, architecture and master planning. His work is complex and is like most art, tied to the personality who made it. His earliest master plans - the Ville 
Contemporaine plan for 3 million inhabitants of 1922 was, like Wright, concerned with bringing in more nature and light into the life of the citizen. The scheme had a central business core with airports and surrounding layers of 12storey mid-rise apartments that spread in a grid, alternating green spaces that segregated pedestrian traffic from cars vehicles. It is important to note that at the time the current traffic we face in most cities wasn't even hinted at, or even understood. These new designs for living "destroyed the continuity of the urban fabric for the first time by proposing huge repetitive objects, freestanding in the middle of giant highways...The average distance between intersections is 400 metres, which is very high and, combined to the width of the roads and the high speed of cars, makes pedestrian travel impossible. The modernist city is a city made for cars" [5].

Corbusier explored rigid geometries and also entirely organic 'Megastructure' that could be compared to rivers or tendrils. He delighted in the master plan. In these later compositions for instance, one scheme for the Bay of Rio de Janeiro in 1929, 10 storeys of housing would float on immense concrete column over the existing built form. On top of this viaduct of residences, would run a motorway 100 metres above the ground. In this manner his scheme was a reaction to the congestion he saw and the beauty of the topography. An equally surreal and enormous design intervention was introduced for Algiers in December of 1932 [6]. In this scheme, beautifully drawn as another snaking highway sitting atop an enormous wall, would be another concept-design to alleviate traffic and housing in one fell swoop. These schemes are responses to his earlier, more reactionary proposals for clearing away large areas of historic cities, in this case Paris, with large cruciform towers arranged far apart for light and air as well as the landing of airplanes [7].

Villa Savoye (1929-31) is a weekend retreat near Paris, at Poissy. He designed this home with his cousin, Pierre Jeanneret as a demonstration of how to live with nature above the ground level. Many of his residential projects reference his Megastructure, and vice-versa, and there is plenty of the testing out of theories in the commissions to reinforce the ideas in his urban plans. There is a delight in geometry and in observing the driving arc of the automobile to determine a suitable floor plan width. They wished to conceal its mass and ostensibly its sounds and smells behind a flattened façade. The doors to the garage are not expressive as in his entryways, especially in the institutional works. The automobile was absorbed into the fabric and facade of the home. The scheme privileges the role of transport, effectively incorporating the ideas and iconography of auto and marine travel, and blending this aesthetic along with a historical fascination of spiral stairs, ramps, classical facades and defensible walls in the plan of the home. Sheltered gardens (fig. 4) that are created on the second and third level (rooftops) champion privacy and nature, and separate vehicles from pedestrians, making it clear that the two should not mix in the same space programmatically (the ground is meant for the unencumbered passage of motor vehicle traffic). In this new world the scent of lavender and diesel will not combine. 


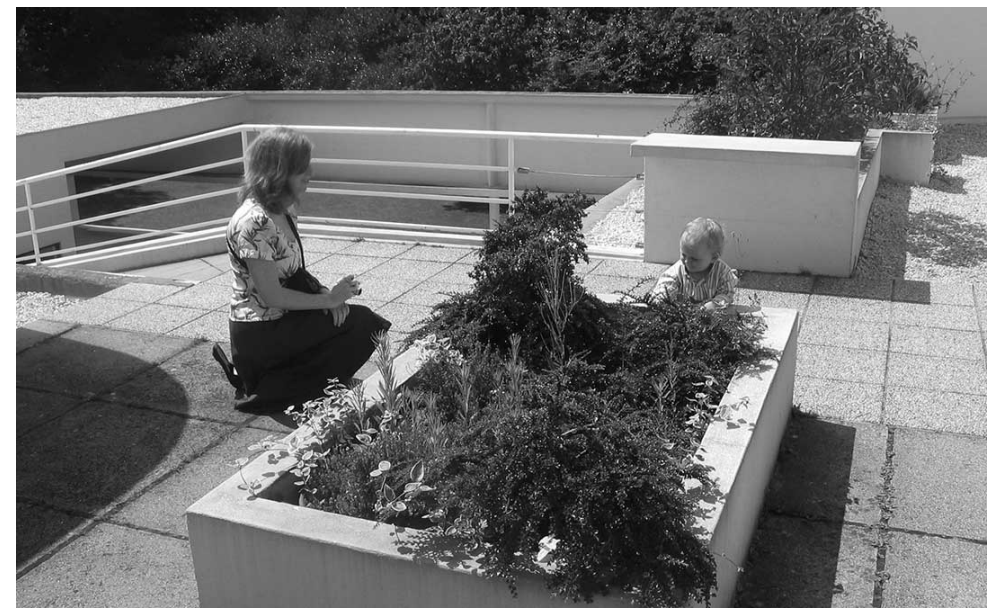

Figure 4: Third floor rooftop garden of the Villa Savoye.

This project has a paradoxical element related to the car and the pedestrian while the exterior approach by car is carefully orchestrated and leaves only one way in and out (to park), the interior and upper platform/roofscape allows for plenty of circulation paths in the home, free from view from the public. This situation reverses itself with his many planning schemes where the vehicle is privileged and is given many opportunities to cross intersections untroubled by crossing pedestrians, since there (shouldn't be any to worry about) wouldn't be anywhere to really walk to as a destination. The pedestrians in these city schemes would stay put on their allotted plots of land or walk on the elevated sidewalks- or take motorized transport to cross the wide expanse of roads.

\section{No to the vertical city}

Frank Lloyd Wright, born in Richland Center, Wisconsin (1867-1959), was a dedicated modernist who developed the Prairie Style (pioneered from 18931920) a horizontal style, and later evolved his mature Organic and Usonian housing that strongly influenced Mies van der Rohe and Le Corbusier, among others. His designs for houses were arguably one of the first starts of twentieth century modernism that championed the destruction of the constricting effects of Victorian domestic life by literally opening up the corners of the box to permit a more permeable inside-outside relationship. These homes exhibited long-roofed, low to the ground drama, celebrating the landscape view, clear geometry and horizontality. They anticipate his trajectory of eschewing the city and all its verticality and hardships- especially at the time of the Great Depression.

He shared with Le Corbusier a clear distaste for congested city living, as it currently existed. His vision was to clear away space, as most modernist images of new projects suggest - the clearing away of the old, the suggestion of open space all around you. The Broadacre City plans were all about experiencing the 
open sky, being situated in enough land for each home to be somewhat independent, and to relate back to the land in a way that city life could not, by taking up a large area of land (approximately one acre) for one homestead. This model was influenced by earlier Garden Beautiful schemes from Europe and in North America that were promoted and tested with some early success.

This image of living was introduced in his book The Disappearing City for the first time in 1932 and it continued to interest him throughout his life. Each family would have enough green space to be partially self-sufficient, given approximately one acre surrounded with roads to ferry families by vehicles everywhere with pedestrian activity largely kept to each plot - most movement accomplished by the car using a network of arterials and local roads [8]. Wright's Broadacre City, ironically named perhaps, is dominated by his desire to introduce lower-cost construction to housing so more American people would be able to live the modern life away from the city. Usonian homes did have a clear place for the car, a defensible front wall with few large picture windows to the street; families retreated to the safety of the back garden. It sounds so vehemently anti-city, naïve in separating the historic centres so as to start a parallel world. Still "it is sobering to realize that this was perhaps the last serious attempt made by any American architect to render the suburb as a place of cultivation" [9].

Wright understood the importance a strong concept had in establishing a direction for future city and suburban planning. He contacted many levels of government to try to get his vision of how the country should dwell and move approved [10]. His aesthetic and dream were unwittingly the source of ideas for the very successful and much copied suburban house construction that followed his experiments in house form; arguably the first truly successful speculative housing construction company after WWII, Levitt \& Sons real-estate developers, of Levittown fame, borrowed many design ideas from Wright in his Usonian housing [10, pp. 113-14].

Contemporary utopian versions of housing by Le Corbusier and Frank Lloyd Wright couldn't be more different and surprisingly the same in certain respects from each other. Both architects saw the contemporary city as alternatively unhygienic, filthy, dangerous, and certainly not what they imagined as representative of their nations' uniqueness and best qualities. They really didn't like the idea that a large space (city) is/was made by many hands, which a city needs to be in order to maintain its grip on modernity and not tilt too far towards either resistance to change (caricature) or reinvention (loss of memory). In each alternative version of a future reality, they saw the automobile as the great connector and emancipator tool for the average citizen, especially the growing middle-classes.

In Wright's version of suburbia (Usonia), the homes should be low, preferably single story with a flat roof. The suburban home grew a sloped roof, largely because of the ease with which water and snow drainage could be solved in as simple a manner as possible, and this required a complement in the facade, borrowing from historic periods, the front of the home, and more importantly, how it was read by the owners when gazing not only out of their living room 
picture windows, but more importantly gazing not at but out from the kitchens and backyards to the communal image of domesticity, the abundant peaked roofs and eventual shrubbery and tree canopies, completed the scene desired. Note that this view was, visually at least, devoid of the cars, that were either proudly displayed on the driveways or sheltered in the garages. Anticipating the contemporary desire (need?) for many cars in a driveway, the constructed models and drawings of Broadacre City homes varied in size and "were defined by the automobile, and the display incorporated examples of 'one-car', 'two-car', and ‘five-car' houses” [10, pp. 113-14].

\section{Conclusion}

In their best work Ludwig Mies van der Rohe, Le Corbusier, and Frank Lloyd Wright are designers who extolled contemporary technology and who were comfortable in their own era, and they did offer a lasting impression on design discourse. Then the question remains-how much extra effort would have been required on the part of these designers to step into the ring and promote and defend the public sphere of North America. In other words, who is going to take responsibility for what modernism has wrought? It is an important question now for sustainable cities everywhere, new and old, this issue of ownership, shared by the community to improve so as to make living a more integrated experience spatially.

Consider the city of Copenhagen who collectively decided to fight against the traffic and parking chaos that engulfed it by the 1960s. Its solution was remarkably simple as a concept-to transform behaviour through design; making parking a car more of a headache by slowly removing available parking spots in the inner city [11]. This happens to be a city with a thriving architectural and design culture - many lauded designers practice and reside here. It is a strong example that design does affect planning change and this in turn impacts the architecture that is made there.

Significant changes in society have impacted the number of drivers; consider that in 1960 to 2001 the average American increased their daily driving from 20.64 miles to over 32 miles. And the purpose of daily trips have shifted significantly since the 1950s with 'work trips' now accounting for only 16 percent of driving compared to the American average of 40 percent [11]. A new generation of creatives will have to decide if the time is right to challenge the dominance of the car and the culture that it demands in order to be satisfied; it has begun in select cities and communities already and much work needs to be done yet. Of the many thousands of early modernist artists, writers, designers, architects, performers, makers - all who took part in making changes, the three selected in this paper have been discussed because their words and ideas spark many reactions and their work still moves us [12] to consider the importance of the unity of space design as an important force in a quality of life.

Contemporary ideas of public use, the many desire lines and overlapping trajectories of multiple parties' rights to the land pull at early simpler notions of site and space. Modernity never worked very well when it was in a vacuum, as 
soon as it was considered from a certain scale - from the area of a city block and beyond, it didn't translate very well from the ink and Mylar into real space. Because of the silent or otherwise political nature to design, a public nature to its being exists and cannot be curtailed by theory alone. It is essential to work design goals through together, or at least come to a compromise because it is one's civic duty, even a corporate duty, and public professional duty, to improve things - because we are quite frankly not starting with a blank canvas anymore.

\section{References}

[1] Snider, G., The Garage (Chapter 6). Some Detached Houses: An Exhibition Curated by Bill Jeffries, Contemporary Art Gallery: Vancouver, p. 54, 1990.

[2] Schwartz, F., Mother's House: The Evolution of Vanna Venturi's House in Chestnut Hill, Rizzoli: New York, p. 22, 1992.

[3] Colomina, B., Privacy and Publicity: modern architecture as mass media, The MIT Press: Woburn, 1994.

[4] Cohen, J. L., Ludwig Mies van der Rohe, Birkhäuser: Boston, p. 166, 2007.

[5] Salet, S., Cities and Forms, CSTB Urban Morphology Lab: Trieste, pp. 275-278, 2011.

[6] Cresti, C. Le Corbusier, The Hamlyn Publishing Group: Toronto, pp. 2633, 1970.

[7] Wilk, C., Modernism: Designing a New World 1914-1939, V\&A Publishing: London, p. 329, 2008 (2006).

[8] Wasmuth Portfolio, http://en.wikipedia.org/wiki/Wasmuth_Portfolio, retrieved (March 14, 2013).

[9] Frampton, K., American Masterworks: The Twentieth Century House, Universe Publishing: New York, p. 71, 2002.

[10] Rosenbaum, A., Usonia: Frank Lloyd Wright's design for America, The Preservation Press, National Trust for Historic Preservation: Washington, 1993.

[11] Vanderbilt, T., Traffic: why we drive the way we do (and what it says about us), Vintage Books: New York, pp. 134-5, 2008.

[12] Norberg-Schulz, C., Functionalism (Chapter 11) Meaning in Western Architecture, Praeger Publishers: New York, 1975. 